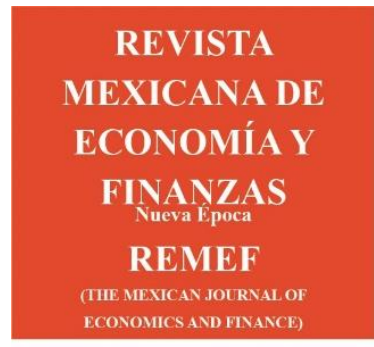

Revista Mexicana de Economía y Finanzas, Nueva Época

Volumen 16 Número 2, Abril - Junio 2021, pp. 1-19, e580

DOI: https://doi.org/10.21919/remef.v16i2.580

(Recibido: 22/junio/2020, aceptado: 28/septiembre/2020 publicado: 1/diciembre/2020)

\title{
La desigualdad y el disímil impacto de la política monetaria
}

\author{
Pablo Cotler ${ }^{1}$ - Universidad Iberoamericana-CDMX, México \\ Rodrigo Carrillo² - Universidad Iberoamericana-CDMX, México
}

Se analiza si cambios en la tasa objetivo del banco central tiene un impacto diferenciado en los distintos municipios del país. Se divide a éstos en cinco grupos según su marginación y se mide el impacto que tienen las variaciones en la tasa objetivo sobre el flujo de préstamos personales y de nómina que reciben los pobladores de los municipios. Utilizando datos panel y metodologías GLS y ARDL-CS, se encuentran dos resultados. Primero, en el caso de los préstamos de nómina, los beneficiados por una baja en la tasa objetivo y los menos afectados cuando dicha tasa sube son los que viven en los municipios de muy baja marginación. Segundo, el volumen de los préstamos personales y de nómina es sensible a las modificaciones en la tasa objetivo sólo en el caso que los pobladores vivan en municipios de baja y muy baja marginación. La originalidad de este trabajo es su enfoque municipal. Su principal implicancia es que en caso la autoridad monetaria desee elevar el impacto geográfico de sus medidas, debe buscar nuevos instrumentos y apoyar a instituciones financieras no-bancarias.

Clasificación JEL: E43, E58, G5.

Palabras clave: Tasa Objetivo, préstamos personales, marginación, desigualdad.

\section{Inequality and the Heterogenous Impact of Monetary Policy}

We analyze whether changes in the central bank's target rate have differentiated impacts in the different municipalities of the country. For such purpose we divide them into five groups according to their marginalization and estimate the impact that changes in the target rate have on the flow of personal and payroll loans. Using panel data and ARDL-CS methodologies, two results are found. First, in the case of payroll loans, those who benefit from a drop in the target rate and those who are least affected when the target rate is increased are those who live in municipalities with very low marginalization. Second, the volume of personal loans and payroll loans are sensitive to changes in the target rate only when people live in municipalities with low and very low marginalization. The originality of this work is its municipal approach. Its main implication is that if the monetary authority wishes to increase its geographical impact, it must look for new instruments and support non-bank financial institutions.

JEL Classification: E43, E58, G5.

Keywords: central bank interest rate, personal loans; marginalization, inequality.

\footnotetext{
${ }^{1}$ Autor de correspondencia. ORCID: 0000-0003-1126-9243

Departamento de Economía, Universidad Iberoamericana. Prol. Paseo de la Reforma 880. Álvaro Obregón, 01210, Ciudad de México. Telf. 5950-4268, Correo: pablo.cotler@ibero.mx

2 ORCID: 0000-0001-6938-3394

*Sin Fuente de financiamiento para el desarrollo de la investigación
} 
"Monetary policy is a blunt tool which certainly affects the distribution of income and wealth..."

[Bernanke,2015].

\section{Introducción}

Desde inicios del 2006, el Banco de México empezó a anunciar su postura de política monetaria por medio de la fijación de una tasa objetivo de interés. Para tal fin, la autoridad altera el saldo de los depósitos de regulación monetaria para lograr que la tasa de interés interbancaria de equilibrio a un día se ajuste al valor de la tasa objetivo. El posible impacto de estas modificaciones sobre otras tasas de interés y sobre el nivel de crédito conducen a que eventualmente puedan darse modificaciones en el dinamismo de corto plazo de la demanda agregada (Bernanke y Blinder, 1992).

En la literatura económica se describen los diversos canales por los que la política monetaria puede alterar en el corto plazo el nivel de actividad económica, siendo uno de ellos el canal crediticio (Bernanke y Gertler, 1995 y Mishkin, 1995). Para medir la contribución de este canal, se utiliza por lo general el método de vectores autorregresivos para comparar qué sucede - ante un cambio en la tasa objetivo - con la función de impulso-respuesta cuando la tasa activa de interés es endógena o exógena. A este respecto, para el caso de México, Castillo (2003), así como Sidaoui y Ramos-Francia (2008) encuentran que incrementos en la tasa objetivo de interés traen consigo un menor dinamismo del crédito bancario. Además, estos últimos hallan que el crédito a personas es menos sensible relativo a lo que sucede con el crédito empresarial - a alteraciones en las tasas de interés. Ibarra (2016) obtiene resultados similares y además encuentra que el impacto de un cambio en la postura de política monetaria sobre la cartera crediticia no es simétrico; el efecto es mayor cuando la tasa objetivo sube.

Si bien los cambios en la postura monetaria se transmiten por diversos mecanismos hacia el nivel de actividad económica, su impacto y temporalidad quedan determinados -entre otros factorespor la estructura financiera, las restricciones de liquidez y la diferencias en el nivel y composición del ingreso y la riqueza. En este sentido, es muy probable que la política monetaria pueda tener impactos distributivos.

De acuerdo a Colciago, Samarina y de Haan (2019), modificaciones en la tasa objetivo pueden alterar la desigualdad del ingreso y de la riqueza. Una primera vía para que ello ocurra a es a través de las diferencias que existen en el portafolio de activos financieros que poseen las personas. Así, dado que una modificación en la tasa objetivo puede alterar los precios de los activos financieros y otras tasas de mercado, el impacto en la riqueza financiera de las personas dependerá de si tienen activos a tasa fija y/o variable y de si éstos son de corto o largo plazo. Por otro lado, una segunda vía proviene del impacto que la política monetaria pudiera tener en el mercado de trabajo y en el de bienes. En este sentido, el posible impacto sobre la desigualdad dependerá de cuáles son las fuentes de ingreso de las personas y en qué sector productivo laboran - ver, por ejemplo, Auclert (2019), Gornemann et al. (2012), Heathcote et al. (2010), y Carpenter y Rodgers (2004). Considerando la información requerida y las dificultades para medir qué sucederá con la desigualdad, Amaral (2017) y Bernanke (2015) sugieren que es muy difícil conocer a priori cuál será el impacto distributivo de una política monetaria. 
En los estudios mencionados se hace énfasis en el cambio que puede darse en el precio de los activos financieros, pero no se considera que sucede con el valor y volumen de crédito. Sin embargo, en México, un porcentaje ínfimo de la población mantiene voluntariamente activos financieros. Por otro lado, a diferencia de lo que acontece en los Estados Unidos (Edwards y Miskin, 1995), en México la captación tradicional y el crédito bancario siguen siendo los productos financieros más utilizados.

Considerando al crédito como un instrumento para suavizar choques negativos -o para financiar proyectos productivos-, diferencias en la probabilidad de firmar contratos crediticios es una vía por medio de la cual el canal crediticio puede tener un impacto distributivo. A este respecto, disparidades en la capacidad para generar garantías crediticias acordes a los criterios bancarios y un acceso desigual a redes para lograr una adecuada reputación crediticia son factores que afectan la posibilidad de firmar contratos crediticios. En caso de que estos factores estuvieran asociados al nivel de riqueza y actividad de las personas, es posible que modificaciones en la tasa objetivo del banco central generen impactos diferenciados en el volumen de préstamos.

Para evaluar dicha hipótesis, exploramos el impacto que tienen los cambios en la postura monetaria sobre la tasa de crecimiento del número de préstamos bancarios otorgados a los individuos en cada municipio. Tomamos el número de créditos bancarios como la variable de interés pues, a diferencia del valor de la cartera, ofrece una mejor descripción de lo que ocurre con la penetración bancaria ante cambios en la postura monetaria. Por otro lado, en ausencia de información socioeconómica de los deudores, tomamos al grado de marginación del municipio donde éstos viven como aproximación de la riqueza individual. Al hacerlo así, examinaremos si cambios en la postura de política monetaria tienen un impacto diferenciado en el volumen de préstamos que reciben los pobladores de municipios de distinta marginación. Para tal fin, el artículo está organizado en cinco secciones adicionales. En la primera sección se presenta una revisión de trabajos actuales en los que se estudian los efectos distributivos de la política monetaria a partir de qué sucede con el precio de distintos activos financieros. Luego, en la segunda sección se describen las principales características del mercado de préstamos de nómina y personales, así como su distribución en los distintos municipios de acuerdo con su grado de marginación2. Con base en dichas características se enuncian las hipótesis del trabajo. Posteriormente en la tercera sección se presentan los datos y las metodologías empíricas que se usarán para evaluar las hipótesis referentes al impacto que tiene un cambio en la postura de política monetaria. En la cuarta sección se presentan los resultados y en la última se discuten los mismos.

El trabajo tiene tres resultados que vale la pena resaltar. Primero, un incremento en la tasa objetivo tiene un impacto sobre el volumen de préstamos que es mayor al que se obtiene cuando se reduce dicha tasa. Es más fácil detener el dinamismo de los nuevos créditos que expandirlos. Segundo, en el caso de los préstamos de nómina, incrementos en la tasa de interés afectan en menor medida a los pobladores de los municipios de muy baja marginación. Además, ante reducciones en la tasa objetivo de interés, el flujo de nuevos préstamos crece más en los municipios de baja marginación. Esto es, la población que vive en los municipios de muy baja marginación son los más beneficiados. Tercero, el volumen de los préstamos personales y de los préstamos de nómina es sensible a las modificaciones en la tasa objetivo solo en el caso que los pobladores vivan en municipios de baja y muy baja marginación. 


\section{Revisión de la Literatura}

Una de las vías más comunes para entender el impacto distributivo de la política monetaria ha sido a través de analizar qué sucede cuando se experimentan procesos inflacionarios. Así, hay textos que examinan cómo la indexación, el comportamiento ${ }^{3}$ heterogéneo de las tasas interés y el uso del efectivo, conducen a que la inflación genere efectos redistributivos - ver por ejemplo los trabajos recientes de Doepke y Schneider (2006), y Erosa y Ventura (2002).

Además, hay también estudios que muestran que aun con una inflación baja y estable la política monetaria puede haber efectos redistributivos. Considerando que cambios en la postura monetaria pueden alterar el precio de los activos, autores como Doepke y Schneider (2006), Auclert (2016), Colciago, Samarina y de Haan (2019), y Evgenidis y Fasianos (2019) muestran que el impacto de la política monetaria sobre la desigualdad depende en buena medida de cómo están constituidos los portafolios financieros de las familias. Así, por ejemplo, en caso de una política monetaria expansiva, aquellos que tienen activos de corto plazo (Cetes 28 días) o deudas de largo plazo a tasa fija (hipotecas) se beneficiaran de la reducción de las tasas reales en el corto plazo. Sin embargo, como explica Bernanke (2015), en caso la composición de los portafolios no esté correlacionada con los niveles de ingreso, es difícil saber de antemano si los cambios en la tasa objetivo tendrán un efecto progresivo o regresivo sobre la distribución del ingreso.

Una vía adicional que puede llevar a que una política monetaria tenga efectos distributivos es cuando el acceso al financiamiento bancario depende del ingreso y riqueza de los potenciales deudores. Como afirman Monnin, Koedijk y Loungani (2018, pp:165) "In practice, income and wealth are major determinants of access to financial markets and, thus, the distribution of income and wealth matters in gauging the direct and indirect reactions of the economy to monetary policy impulses." Considerando al crédito como un instrumento para suavizar choques negativos o para financiar proyectos productivos, diferencias en la probabilidad de firmar contratos crediticios es una vía por medio de la cual el canal crediticio puede generar un impacto distributivo. A fin de examinar dicha posibilidad, este artículo analiza si los cambios en la tasa objetivo del banco central generan variaciones en el nivel de financiamiento que dependen del nivel de riqueza. Si ello fuera así, una política monetaria expansiva tendrá un menor impacto en las poblaciones más pobres y con ello pudiera agravarse las desigualdades ya existentes.

\section{Características de los Préstamos Personales y de Nómina}

En la actualidad, la banca ofrece tres productos financieros que permiten a un individuo la adquisición de bienes de consumo: los préstamos personales, los préstamos de nómina y las tarjetas

\footnotetext{
${ }^{3}$ Para octubre del 2019, había 20 millones de préstamos personales y de nómina vigentes con un saldo a deber de 500 mil millones de pesos. El otro producto de consumo eran las tarjetas de crédito. En ese mismo mes había 26 millones de tarjetas de crédito con un saldo a deber de 340 mil millones de pesos.
} 
de crédito4. Un requisito fundamental para obtener un préstamo personal es tener una cuenta bancaria en la institución donde se solicita dicho producto. Gracias a ello, el banco tiene información privilegiada que le permite decidir cuánto ofrecer y cuánto cobrar. Si bien el deudor no necesariamente consigue el monto deseado, un préstamo personal se puede obtener muy rápidamente. En cambio, los préstamos de nómina requieren que el solicitante trabaje en una empresa formal, que dicho establecimiento tenga una cuenta bancaria en donde el solicitante desea pedir el préstamo y que el administrador de la empresa se comprometa a la retención y transferencia periódica de la suma requerida para el pago de la deuda. Si bien los préstamos personales tienen menores costos de transacción, el compromiso del empresario a cubrir la deuda por medio de las retenciones al salario o de la liquidación, hacen que los préstamos de nómina sean por lo general más baratos.

Para octubre del 2019, había 20 millones de préstamos personales y de nómina, y el saldo a deber era de 500 mil millones de pesos. Asumiendo que el importe original de los préstamos concedidos estuviera correlacionado con el ingreso promedio de los deudores, los cuadros 1 y 2 muestran que para octubre de 2019 estos productos eran utilizados por individuos de muy distintos niveles de ingreso. Sin embargo, los préstamos personales tienen una distribución más sesgada hacia montos inferiores y sus principales oferentes destacan por ser bancos-tienda de capital nacional, y cuyos activos eran inferiores al cinco por ciento del sistema bancario. A diferencia de estos, las entidades bancarias que dominan el mercado de préstanos de nómina son bancos que pertenecen a redes globales y cuyos activos equivalen al sesenta por ciento de los activos del sistema bancario. Estos rasgos que se observan en este mes en particular se mantienen a lo largo del período 20112019. En el caso de los préstamos personales, Banco Azteca y Banco Famsa fueron los principales oferentes con una participación de mercado del setenta por ciento y en el caso de los préstamos de nómina fueron BBVA y Citibanamex con el sesenta por ciento.

Cuadro 1. Participación en el Mercado de Préstamos Personales de los Cuatro oferentes más importantes, por importe original del préstamo (octubre 2019)

\begin{tabular}{|l|c|c|c|c|c|c|}
\hline \multicolumn{1}{|c|}{ Intervalo de Línea } & Azteca & Famsa & Bansefi & $\begin{array}{c}\text { Bancoppe } \\
\text { l }\end{array}$ & $\begin{array}{c}\text { Participació } \\
\text { n de los } \\
\text { cuatro } \\
\text { bancos }\end{array}$ & $\begin{array}{c}\text { Distribución Porcentual } \\
\text { acumulada del número } \\
\text { de préstamos } \\
\text { del sistema bancario }\end{array}$ \\
\hline Menos de 3,000 pesos & 61.6 & 17.7 & 18.5 & 1.4 & 99.2 & $38.1 \%$ \\
\hline Menos 5,000 pesos & 60.4 & 20.5 & 15.2 & 2.8 & 98.8 & $46.9 \%$ \\
\hline Menos de 10,000 pesos & 63.5 & 19.8 & 10.6 & 4.2 & 98.1 & $67.1 \%$ \\
\hline Menos de 50,000 pesos & 58.2 & 19.0 & 7.9 & 5.0 & 90.1 & $90.3 \%$ \\
\hline
\end{tabular}

\footnotetext{
${ }^{4}$ En este trabajo las tarjetas de crédito no fueron consideradas por tres motivos. Primero, porque sus datos a nivel municipal provienen de una fuente (Reportes de inclusión financiera) distinta a la utilizada para los préstamos de nómina y personales (Portafolio de información). Segundo, porque la información de los Reportes es trimestral mientras que las del Portafolio es bimestral. Y tercero, porque es probable que el comportamiento de los oferentes y demandantes de financiamiento sea distinto cuando el producto financiero es revolvente -la tarjeta de crédito que cuando es no-revolvente- los préstamos personales y de nómina.
} 


\begin{tabular}{|c|c|c|c|c|c|c|}
\hline $\begin{array}{l}\text { Menos de } \\
100,000 \text { pesos }\end{array}$ & 55.3 & 18.3 & 7.5 & 4.8 & 85.9 & $95.1 \%$ \\
\hline Más de 100,000 pesos & 0.1 & 2.0 & 0.0 & 0.0 & 2.1 & $4.9 \%$ \\
\hline Total & 52.6 & 17.5 & 7.1 & 4.5 & 81.7 & $100.0 \%$ \\
\hline
\end{tabular}

Fuente: Elaboración con datos de https://www.cnbv.gob.mx/Paginas/PortafolioDeInformacion.aspx Página visitada el 05/03/20

Cuadro 2. Participación en el Mercado de Préstamos de Nómina de los Cuatro oferentes más importantes, por importe original del préstamo(octubre 2019)

\begin{tabular}{|l|c|c|c|c|c|c|}
\hline \multicolumn{1}{|c|}{ Intervalo de Línea } & Citibank & BBVA & Banorte & Santander & $\begin{array}{c}\text { Participaci } \\
\text { ón de los } \\
\text { cuatro } \\
\text { bancos }\end{array}$ & $\begin{array}{c}\text { Distribución } \\
\text { Porcentual } \\
\text { acumulada del } \\
\text { número de } \\
\text { préstamos del } \\
\text { sistema bancario }\end{array}$ \\
\hline $\begin{array}{l}\text { Menos de 3,000 } \\
\text { pesos }\end{array}$ & 2.2 & 47.9 & 27.1 & 0.5 & 77.7 & $8.5 \%$ \\
\hline \multicolumn{1}{|c|}{ Menos 5,000 pesos } & 3.6 & 45.8 & 26.4 & 4.5 & 80.3 & $12.6 \%$ \\
\hline $\begin{array}{l}\text { Menos de 10,000 } \\
\text { pesos }\end{array}$ & 6.1 & 44.4 & 24.1 & 7.4 & 82.0 & $19.9 \%$ \\
\hline $\begin{array}{l}\text { Menos de 50,000 } \\
\text { pesos }\end{array}$ & 16.0 & 38.3 & 18.5 & 11.5 & 84.3 & $62.1 \%$ \\
\hline $\begin{array}{l}\text { Menos de 100,000 } \\
\text { pesos }\end{array}$ & 17.2 & 38.2 & 17.1 & 12.8 & 85.3 & $80.8 \%$ \\
\hline $\begin{array}{l}\text { Más de 100,000 } \\
\text { pesos }\end{array}$ & 22.4 & 35.4 & 13.2 & 19.6 & 90.6 & $19.2 \%$ \\
\hline \multicolumn{7}{|l|}{ Total } \\
\hline
\end{tabular}

Fuente: Elaboración con datos de https://www.cnbv.gob.mx/Paginas/PortafolioDeInformacion.aspx Página visitada el 05/03/20.

Cambios en la tasa objetivo del Banco Central debieran traer consigo variaciones en la tasa de interés y/o en la disposición a prestar. En este sentido, políticas monetarias menos (más) restrictivas deberían reflejarse en un incremento (decremento) de la tasa de crecimiento del volumen de préstamos. Sin embargo, durante los años 2011-2019, la gráfica 1 muestra un comportamiento del número de préstamos personales y de nómina que no necesariamente va acorde con tal descripción. Dos factores pueden explicar tal situación. Un primer factor es la disposición a prestar por parte de las instituciones bancarias y la disposición de las familias a solicitar un financiamiento. Durante el periodo 2011-2019, la tasa objetivo del banco central cambió en 23 ocasiones. Aun cuando dichas variaciones no se dieron bajo una frecuencia preestablecida, es probable que los bancos tomaran sus decisiones crediticias con base en sus predicciones de futuros cambios en la tasa objetivo, lo cual pudiera restar valor al impacto contemporáneo de las variaciones en la tasa objetivo. Un segundo factor son las expectativas referentes al ingreso futuro de las familias. 
En este sentido, bien puede ocurrir que, a pesar de una baja en la tasa objetivo del banco central, las entidades bancarias no alteren su postura a prestar o que el sector privado no altere su demanda.

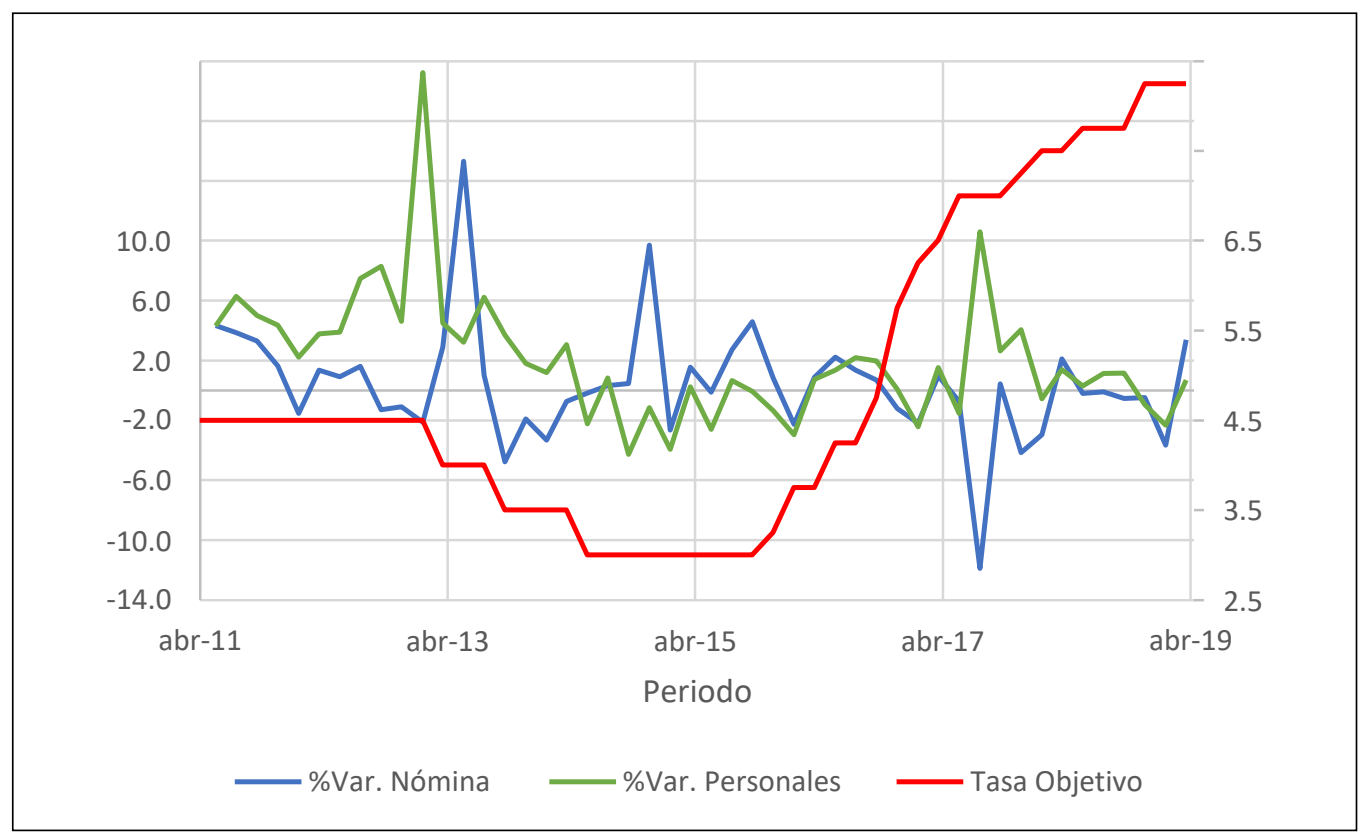

Gráfica 1. Variación porcentual de Créditos por cada 10 mil adultos y Tasa Objetivo del Banco Central

Fuente: Elaboración propia con datos de la CNBV y Banxico

A este respecto, los rasgos distintivos de los préstamos de nómina y personales permiten plantear tres hipótesis referentes a la relación que guarda el flujo de nuevos préstamos ante cambios en la tasa objetivo de interés. Primero, la asimetría en los costos de transacción para expandir y reducir el flujo de nuevos préstamos permite suponer que las alzas y reducciones en la tasa objetivo tendrán un impacto diferenciado. Así, se espera que el flujo de nuevos préstamos se alteré más cuando la tasa objetivo sube que cuando se reduce. Segundo, considerando sus bajos costos de transacción, el flujo de nuevos préstamos personales es -relativo a lo que acontece con los préstamos de nómina- más sensible a los cambios en la tasa objetivo de interés y al ciclo económico. Tercero, considerando que ambos tipos de préstamos requieren de garantías, cierto grado de formalidad laboral y de inclusión financiera, es probable observar un comportamiento heterogéneo. En particular, se espera que incrementos en la tasa objetivo tengan un mayor impacto en el flujo de nuevos préstamos en zonas de marginación superior y que reducciones en la tasa objetivo tengan un mayor impacto en zonas de menor marginación. Esto es, las diferencias socioeconómicas entre poblaciones, medidas por el grado de marginación municipal, ocasionan que los cambios en la política monetaria puedan agravar las desventajas que enfrentan los pobladores de los municipios más desfavorecidos. 


\section{Datos y metodología}

Para efectos de evaluar las hipótesis antes mencionadas, los datos correspondientes a la tasa objetivo se obtuvieron del Banco de México y el volumen de préstamos personales y de nómina de la Comisión Nacional Bancaria y de Valores (CNBV). Estos datos están desagregados a nivel municipal, tienen una periodicidad bimestral y abarcan el período comprendido entre el segundo bimestre del 2011 y el segundo bimestre del 2019. Además, se utilizan los datos de la tasa de morosidad de estos dos tipos de préstamos, la participación de mercado de los dos bancos más importantes para cada uno de los productos financieros en los distintos municipios, el número de cuentas tradicionales con respecto al número total de cuentas en cada municipio (CNBV), los datos desestacionalizados del índice trimestral de actividad económica estatal (INEGI), y el grado de marginación municipal con base en datos de la Encuesta Intercensal 2015 (CONAPO) ${ }^{5}$.

Siendo la variable de interés el cambio en el volumen de los préstamos por cada diez mil adultos, se seleccionaron los municipios con registros consecutivos de al menos un año. Debido a ello, al hacer estimaciones utilizando el número de créditos de nómina se descartó al treinta por ciento de los 2,465 municipios que tiene el país y al cuarenta por ciento al utilizar el número de créditos personales ${ }^{6}$. Asimismo, se omitieron los registros del último percentil del cambio en el número de créditos con en el fin de evitar datos atípicos 7 . En el cuadro 3 se presentan las estadísticas básicas de las variables que se utilizarán.

Cuadro 3. Estadísticas Básicas

\begin{tabular}{|c|c|c|c|c|c|c|c|}
\hline \multirow{2}{*}{\multicolumn{2}{|c|}{ Variable }} & \multicolumn{3}{|c|}{ Créditos de nómina } & \multicolumn{3}{|c|}{ Créditos personales } \\
\hline & & Media & Desv. Est. & Obs. & Media & Desv. Est. & Obs. \\
\hline \multirow{3}{*}{$\begin{array}{l}\text { Log. Número } \\
\text { de créditos }\end{array}$} & General & 5.4 & 0.9 & 83,545 & 5.7 & 1.5 & 72,569 \\
\hline & Al interior de grupos & & 0.9 & 1,705 & & 1.2 & 1,481 \\
\hline & Entre grupos & & 0.2 & 49 & & 0.8 & 49 \\
\hline \multirow{5}{*}{$\begin{array}{l}\text { Tasa de } \\
\text { interés } \\
\text { objetivo }\end{array}$} & General & 4.9 & 1.7 & 83,545 & 4.9 & 1.7 & 72,569 \\
\hline & Al interior de grupos & & 0.0 & 1,705 & & 0.0 & 1,481 \\
\hline & Entre grupos & & 1.7 & 49 & & 1.7 & 49 \\
\hline & General & 4.7 & 0.1 & 81,840 & 4.7 & 0.1 & 71,088 \\
\hline & Al interior de grupos & & 0.0 & 1,705 & & 0.0 & 1,481 \\
\hline
\end{tabular}

\footnotetext{
${ }^{5}$ El periodo base para el índice trimestral de actividad económica estatal (ITAEE) es junio 2013. Para el número de créditos de nómina y personales se verificó si el componente estacional es significativo al 90 por ciento de confianza para el agregado nacional. Solo resultó significativo el número de créditos de nómina. Sin embargo, se decidió mantenerla sin desestacionalizar pues los resultados de las estimaciones no varían significativamente cuando se les compara con los obtenidos con la variable desestacionalizada.

${ }^{6}$ Para el caso de créditos de nómina, 746 municipios fueron descartados por tener pocos datos de crédito y los otros 14 fueron por carecer de registros en algún periodo. Mientras que para los créditos personales no fueron considerados 971 municipios por tener pocos datos y 14 más por no contar con registros para algún periodo. En ambos casos, aproximadamente la mitad de los municipios excluidos estaban localizados en Oaxaca.

${ }^{7}$ Con ello, se omiten 1,113 observaciones de crédito de nómina, de las cuales el 42.4 por ciento corresponden al cuarto bimestre de 2011 y al tercer bimestre de 2017. Así como 1,126 observaciones de crédito personal, de las cuales 87.3 por ciento se concentran en el quinto bimestre de 2017 y cuarto bimestre de 2018.
} 


\begin{tabular}{|c|c|c|c|c|c|c|c|}
\hline Log. ITAEE & Entre grupos & & 0.1 & 48 & & 0.1 & 48 \\
\hline \multirow{3}{*}{$\begin{array}{l}\text { Tasa de } \\
\text { morosida } \\
\text { d }\end{array}$} & General & 9.8 & 5.8 & 80,135 & 16.0 & 8.0 & 66,645 \\
\hline & $\mathrm{Al}$ interior de grupos & & 2.1 & 1,705 & & 3.1 & 1,481 \\
\hline & Entre grupos & & 5.4 & 47 & & 7.3 & 45 \\
\hline \multirow{3}{*}{$\begin{array}{l}\text { Participación } \\
\text { principales } \\
\text { dos oferentes }\end{array}$} & General & 76.9 & 12.4 & 83,545 & 75.2 & 14.5 & 72,569 \\
\hline & $\mathrm{Al}$ interior de grupos & & 10.7 & 1,705 & & 9.7 & 1,481 \\
\hline & Entre grupos & & 6.3 & 49 & & 10.7 & 49 \\
\hline \multirow{3}{*}{$\begin{array}{l}\text { Proporción } \\
\text { cuentas } \\
\text { tradicionale } \\
\text { S }\end{array}$} & General & 65.7 & 39.4 & 83,545 & 64.9 & 39.9 & 72,569 \\
\hline & Al interior de grupos & & 20.2 & 1,705 & & 20.0 & 1,481 \\
\hline & Entre grupos & & 33.9 & 49 & & 34.5 & 49 \\
\hline
\end{tabular}

Fuente: Elaboración propia con base en datos de Banxico y CNBV.

Para analizar si la sensibilidad del flujo de nuevos créditos ante cambios en la tasa objetivo varía por la riqueza del municipio, se agruparon a estos últimos en cinco grupos de acuerdo a su grado de marginación. En el Cuadro 4 se muestra la distribución de los préstamos, el tamaño relativo de la población y un indicador del uso de cuenta bancarias por tipo de municipio.

Cuadro 4. Distribución de Prestamos por Grado de Marginalidad Municipal, abril 2019

\begin{tabular}{|c|c|c|c|c|c|c|c|c|}
\hline \multirow[b]{2}{*}{$\begin{array}{l}\text { Grado de } \\
\text { Marginación } \\
\text { Municipal }\end{array}$} & \multirow[b]{2}{*}{$\begin{array}{c}\% \\
\text { Població } \\
\text { n adulta } \\
2019\end{array}$} & \multirow[b]{2}{*}{$\begin{array}{l}\text { Cuentas } \\
\text { bancaria } \\
\text { s por } \\
\text { cada } \\
10,000 \\
\text { adultos }\end{array}$} & \multicolumn{3}{|c|}{ Créditos de nómina } & \multicolumn{3}{|c|}{ Créditos personales } \\
\hline & & & $\begin{array}{l}\text { Distribució } \\
\text { n de } \\
\text { préstamos }\end{array}$ & $\begin{array}{c}\text { Número } \\
\text { de } \\
\text { municipio } \\
\text { s donde se } \\
\text { ubican los } \\
\text { deudores }\end{array}$ & $\begin{array}{c}\% \text { de } \\
\text { municipio } \\
\text { s en la } \\
\text { muestra } \\
\text { respecto } \\
\text { del total } \\
\text { de } \\
\text { municipio } \\
\text { s }\end{array}$ & $\begin{array}{l}\text { Distribució } \\
\text { n de } \\
\text { préstamos }\end{array}$ & $\begin{array}{l}\text { Número } \\
\text { de } \\
\text { municipio } \\
\text { s donde se } \\
\text { ubican los } \\
\text { deudores }\end{array}$ & $\begin{array}{c}\% \text { de } \\
\text { municipio } \\
\text { s en la } \\
\text { muestra } \\
\text { respecto } \\
\text { del total } \\
\text { de } \\
\text { municipio } \\
\text { s }\end{array}$ \\
\hline Muy bajo & $61.9 \%$ & 14,523 & $77.1 \%$ & 310 & $89.9 \%$ & $65.4 \%$ & 316 & $91.6 \%$ \\
\hline Bajo & $16.4 \%$ & 7,045 & $13.4 \%$ & 405 & $81.3 \%$ & $16.8 \%$ & 394 & $79.1 \%$ \\
\hline Medio & $9.6 \%$ & 4,468 & $5.4 \%$ & 393 & $76.5 \%$ & $9.6 \%$ & 305 & $59.3 \%$ \\
\hline Alto & $9.2 \%$ & 2,516 & $3.6 \%$ & 468 & $57.3 \%$ & $7.3 \%$ & 348 & $42.6 \%$ \\
\hline Muy alto & $2.9 \%$ & 840 & $0.5 \%$ & 129 & $45.6 \%$ & $0.9 \%$ & 117 & $41.3 \%$ \\
\hline Total & $100.0 \%$ & 10,656 & $100.0 \%$ & 1,705 & $69.4 \%$ & $100.0 \%$ & 1,480 & $60.2 \%$ \\
\hline
\end{tabular}

Fuente: Elaboración propia con base en datos de CONAPO y CNBV.

Con el fin de evaluar la hipótesis concerniente a un comportamiento diferenciado del número de préstamos cuando la tasa objetivo sube o baja, se estimó el siguiente modelo:

$$
\Delta y_{i t}=\alpha+\beta X_{t-1}+\gamma \Delta y_{i, t-1}+\delta \Delta z_{i, t-1}+n_{i}+\varepsilon_{i t}
$$

Donde $y_{i t}$ es el logaritmo del número de préstamos por cada 10 mil adultos en el municipio i en el periodo $t$. Con respecto a las variables explicativas, $X$ es un vector compuesto en primer lugar por dos variables dicotómicas que indican si la tasa de interés objetivo del banco central aumentó o disminuyó. Además, con fines de controlar los posibles movimientos de la oferta y demanda de préstamos, en $X$ también están incluidas la tasa de mora ponderada por tamaño de población y la participación de mercado de los dos oferentes más importantes para cada producto financiero en 
cada municipio. La variable participación busca recoger el grado de competencia al interior de cada mercado y con ello las posibles estrategias de colocación de los bancos. Por último, z corresponde al logaritmo del índice trimestral desestacionalizado de la actividad económica estatal (ITAEE) —el cual ayuda a controlar por los cambios en la demanda por financiamiento-y como efecto fijo está el índice de marginación del municipio. Con el fin de corregir la presencia de correlación contemporánea, heteroscedasticidad y correlación serial, la ecuación (1) se estimó mediante Mínimos Cuadrados Generalizados (GLS).

En caso de que el término de error tenga raíz unitaria, la ecuación (1) impide observar cuál es la relación de largo plazo entre la variable dependiente y sus regresores. Más aun, la forma funcional de la ecuación (1) asume que el cambio en la tasa de interés es homogéneo e independientemente del nivel previo y de la magnitud de su variación anterior. Siendo ello posiblemente erróneo, se especificó - siguiendo a Pesaran et al. (1995 y 1999) - un modelo autorregresivo con retardos distribuidos (ARDL) de orden $(p, q 1, \ldots, q \mathrm{k})$, el cual se estimó mediante máxima verosimilitud y para el cual la selección óptima de rezagos se hizo de acuerdo con los criterios de información Bayesiano y de Akaike. Este modelo en su forma de corrección de errores se expresa como:

$$
\Delta y_{i t}=\phi_{i}\left(y_{i, t-1}-\theta_{i}^{\prime} X_{i t}\right)+\sum_{\mathrm{j}=1}^{p-1} \lambda_{i j} \Delta y_{i, t-1}+\sum_{\mathrm{j}=0}^{q-1} \delta_{i j}^{\prime} \Delta X_{i, t-j}+u_{i t}
$$

Al igual que en la ecuación (1), la variable $y_{i t}$ es el logaritmo del número de préstamos por cada 10 mil adultos. Ahora la matriz $X$ incluye a la tasa de interés objetivo, al logaritmo del ITAEE, a la tasa de mora ponderada por tamaño de población, a la participación de mercado de los dos oferentes más importantes para cada producto financiero en cada municipio y al número de cuentas tradicionales en cada municipio como porcentaje del total de cuentas en cada municipio. Además, $\phi \mathrm{i}$ es el término de corrección de error, $\theta$ i los coeficientes de largo plazo, y $\lambda_{i j} y \delta_{i j}$ son los coeficientes de corto plazo para el rezago de la variable dependiente y para los regresores, respectivamente. La principal ventaja de este enfoque es que permite el uso de variables con distinto orden de integración.

Sin embargo, en muestras grandes es posible la presencia de correlación contemporánea, es decir, no se cumple el supuesto $E\left[u_{i t} \mid X_{i t}\right]=0$, donde $u_{i t}=\mu_{i}+\varepsilon_{i t}$. Ante ello, siguiendo a la ecuación (2), se especificó un modelo de tipo autorregresivo con retardos distribuidos de forma transversal (CS-ARDL), como el propuesto en Chudik et al. (2016) para situaciones en que $E\left[u_{i t} \mid X_{i t}\right] \neq 0$, de modo que:

$$
\Delta y_{i t}=\phi_{i}\left(y_{i, t-1}-\theta_{i}^{\prime} X_{i t}\right)+\sum_{j=1}^{p-1} \lambda_{i j} \Delta y_{i, t-1}+\sum_{j=0}^{q-1} \delta_{i j}^{\prime} \Delta X_{i, t-j}+\sum_{j=1}^{p-1} \gamma_{i j} \Delta \bar{y}_{t-1}+\sum_{j=0}^{q-1} \eta_{i j}^{\prime} \Delta \bar{X}_{t-j}+u_{i j}
$$

Donde $\quad \bar{y}_{t}=N^{-1} \sum_{i=1}^{N} y_{i t} \quad$ y $\quad \bar{X}_{t}=N^{-1} \sum_{i=1}^{N} X_{i t}$, los cuales buscan controlar potenciales situaciones que impactan a todos los municipios simultáneamente. ${ }^{8}$

\footnotetext{
${ }^{8}$ Una desventaja de este método radica en que las variables explicativas se incluyen en la estimación de los parámetros de corto y largo plazo, además de su promedio para cada periodo, lo cual implica un incremento
} 


\section{Resultados}

En los cuadros 5 y 6 se presentan los resultados del modelo GLS para cada uno de los dos tipos de préstamos. En la primera columna se presentan los resultados del panel constituido por todos los municipios considerados en la muestra. En las subsiguientes columnas, aparecen los resultados para cada uno de los cinco posibles paneles de acuerdo al grado de marginación de cada municipio. A partir de estos dos cuadros podemos ver que la primera hipótesis no puede ser rechazada en ningún panel: la tasa de crecimiento del número de contratos crediticios es - con una excepción- más sensible cuando la tasa sube que cuando baja. La segunda hipótesis tampoco puede rechazarse en ninguno de los cinco paneles: los créditos personales reaccionan más a los cambios en la tasa objetivo y son más sensible a las variaciones de la actividad económica. Con respecto a la tercera hipótesis, en el caso de los préstamos de nómina, cambios en la tasa objetivo tienen un impacto distintivo para los pobladores viviendo en municipios de muy baja marginación. Así, por ejemplo, una baja en la tasa objetivo solo expande los préstamos en los municipios de muy baja marginación. Y, en caso de incrementos en la tasa, son los pobladores de estos mismos municipios los menos afectados por una baja en el dinamismo de estos préstamos. En este sentido, los cambios de postura monetaria ofrecen mayores beneficios a los pobladores de los municipios menos marginados.

Con respecto a los demás regresores, la variable morosidad viene acompañado — como era de esperar - de un signo negativo. Por otro lado, el índice de marginación de cada municipio resultó ser - para algunos paneles - una variable estadísticamente significativa para explicar el comportamiento de los préstamos personales. Así, al interior de los paneles de muy baja y baja marginación, aquellos municipios con mayor marginación experimentaron un mayor crecimiento en los préstamos personales mientras que lo opuesto sucede en el panel de muy alta marginación. Esto es, al buscar atender a poblaciones en municipios de mayor marginación, los bancos ofrecieron más préstamos a aquello ubicados los paneles de menor marginación.

Un resultado que vale la pena resaltar en las estimaciones de los cuadros 5 y 6 es el referente al signo del parámetro que acompaña a la variable "participación de mercado de los dos principales oferentes". En ambos mercados el parámetro es estadísticamente significativo. Pero, mientras en el caso de los préstamos de nómina el parámetro tiene un signo positivo, en el otro mercado registra un signo negativo. Ello puede ser resultado de dos estrategias bancarias distintas que surgen del nivel de competencia existente. En el mercado de préstamos de nómina, los tres bancos más importantes poseen una participación relativamente similar y son instituciones con un nivel de activos no muy lejanos entre sí. Ello permite suponer que existe bastante competencia en los mercados de préstamos de nómina y que los bancos cuidan su participación9. En este contexto, un incremento en la

exponencial en el número de los regresores y reduce los grados de libertad de la estimación. Ello limita de forma importante el número de controles a incluir. Además de los controles ya señalados en el texto, se analizaron la tasa de informalidad estatal, el saldo promedio de las cuentas tradicionales en cada municipio y la importancia relativa de la banca móvil. Estas, sin embargo, resultaron ser no significativas.

9 Durante el período 2011-2019, BBVA mantuvo una participación promedio de 35\% y sus dos principales competidores bancarios fueron Citibanamex con 24\% y Banorte con 17\%. Dándole un valor de 100 a los activos de BBVA durante el periodo, Citibanamex tuvo activos por valor de 74 y Banorte de 55. A diferencia de ese mercado, en el caso de los préstamos personales, Banco Azteca mantuvo una participación promedio de $47 \%$ y sus dos principales competidores bancarios fueron Banco Ahorro Famsa con 22\% y Citibanamex con 5\%. Considerando que 
participación del líder puede conducir a que en un futuro cercano sus demás competidores busquen expandir su volumen de préstamos para no perder su participación. Tal conducta se reflejaría en un parámetro positivo para la variable "participación de mercado de los dos principales oferentes". Por otro lado, en el caso de los préstamos personales, Banco Azteca y Banco Famsa tiene una participación de mercado muy superior a la de sus competidores más cercanos lo cual permite suponer que existe un bajo grado de competencia en estos mercados. Ante ello, es posible que en caso los bancos con menor participación reduzcan sus préstamos ello no necesariamente ocasionará un incremento en los préstamos de los bancos líderes.

Cuadro 5. Estimación GLS

\begin{tabular}{|c|c|c|c|c|c|c|}
\hline \multicolumn{7}{|c|}{ Variable dependiente: Variación del logaritmo del número de préstamos nómina por cada 10 mil adultos } \\
\hline & $\begin{array}{l}\text { Todos los } \\
\text { municipios }\end{array}$ & $\begin{array}{c}\text { Muy baja } \\
\text { marginación }\end{array}$ & $\begin{array}{c}\text { Baja } \\
\text { marginación }\end{array}$ & $\begin{array}{c}\text { Media } \\
\text { marginación }\end{array}$ & $\begin{array}{c}\text { Alta } \\
\text { marginación }\end{array}$ & $\begin{array}{c}\text { Muy alta } \\
\text { marginación }\end{array}$ \\
\hline $\begin{array}{l}\text { Tasa objetivo } \\
\text { disminuye rezagada }\end{array}$ & $\begin{array}{c}-0.886 \\
(1.07)\end{array}$ & $\begin{array}{c}-1.460^{* * *} \\
(0.37)\end{array}$ & $\begin{array}{c}-0.375 \\
(0.65)\end{array}$ & $\begin{array}{c}-0.124 \\
(0.66)\end{array}$ & $\begin{array}{c}-1.115 \\
(1.14)\end{array}$ & $\begin{array}{l}0.068 \\
(0.78)\end{array}$ \\
\hline $\begin{array}{l}\text { Tasa objetivo } \\
\text { aumenta rezagada }\end{array}$ & $\begin{array}{c}-1.987^{* *} \\
(0.67)\end{array}$ & $\begin{array}{c}-0.870^{* * *} \\
(0.23)\end{array}$ & $\begin{array}{c}-1.218^{* *} \\
(0.41)\end{array}$ & $\begin{array}{c}-1.280^{* *} \\
(0.41)\end{array}$ & $\begin{array}{l}-1.359 \\
(0.71)\end{array}$ & $\begin{array}{c}-1.535^{* *} \\
(0.48)\end{array}$ \\
\hline $\begin{array}{l}\text { Variación \% ITAEE } \\
\text { rezagada }\end{array}$ & $\begin{array}{c}-0.277^{*} \\
(0.13)\end{array}$ & $\begin{array}{c}-0.059 \\
(0.03)\end{array}$ & $\begin{array}{c}-0.141 \\
(0.07)\end{array}$ & $\begin{array}{c}-0.242^{* *} \\
(0.07)\end{array}$ & $\begin{array}{l}-0.256 \\
(0.14)\end{array}$ & $\begin{array}{c}-0.236^{* *} \\
(0.07)\end{array}$ \\
\hline Tasa de morosidad rezagada & $\begin{array}{c}-0.193^{* * *} \\
(0.01)\end{array}$ & $\begin{array}{c}-0.194^{* * *} \\
(0.00)\end{array}$ & $\begin{array}{c}-0.147^{* * *} \\
(0.01)\end{array}$ & $\begin{array}{c}-0.168^{* * *} \\
(0.01)\end{array}$ & $\begin{array}{c}-0.190^{* * *} \\
(0.01)\end{array}$ & $\begin{array}{c}-0.195^{* * *} \\
(0.01)\end{array}$ \\
\hline $\begin{array}{l}\text { Participación de } \\
\text { principales dos oferentes } \\
\text { rezagada }\end{array}$ & $\begin{array}{c}0.025^{*} \\
(0.01)\end{array}$ & $\begin{array}{c}0.051^{* * *} \\
(0.00)\end{array}$ & $\begin{array}{l}0.003 \\
(0.00)\end{array}$ & $\begin{array}{c}0.036^{* * *} \\
(0.00)\end{array}$ & $\begin{array}{c}0.039^{* * *} \\
(0.01)\end{array}$ & $\begin{array}{c}0.038^{* * *} \\
(0.00)\end{array}$ \\
\hline $\begin{array}{l}\text { Variable } \\
\text { dependiente } \\
\text { rezagada }\end{array}$ & $\begin{array}{c}-0.064^{* *} \\
(0.02)\end{array}$ & $\begin{array}{c}-0.118^{* * *} \\
(0.01)\end{array}$ & $\begin{array}{c}-0.075^{* * *} \\
(0.01)\end{array}$ & $\begin{array}{c}-0.065^{* * *} \\
(0.01)\end{array}$ & $\begin{array}{l}-0.025 \\
(0.02)\end{array}$ & $\begin{array}{l}-0.060^{* * *} \\
\quad(0.01)\end{array}$ \\
\hline Índice de marginación & $\begin{array}{l}0.198 \\
(0.24)\end{array}$ & $\begin{array}{c}-0.423 \\
(0.36) \\
\end{array}$ & $\begin{array}{l}-0.457 \\
(0.46) \\
\end{array}$ & $\begin{array}{l}-0.245 \\
(0.82) \\
\end{array}$ & $\begin{array}{l}-0.180 \\
(0.35) \\
\end{array}$ & $\begin{array}{c}-0.443^{*} \\
(0.19)\end{array}$ \\
\hline Constante & $\begin{array}{c}0.573 \\
(1.184) \\
\end{array}$ & $\begin{array}{c}-4.355^{* * *} \\
(0.72) \\
\end{array}$ & $\begin{array}{l}1.172 \\
(0.84) \\
\end{array}$ & $\begin{array}{c}-1.736 \\
(0.93) \\
\end{array}$ & $\begin{array}{r}-1.321 \\
(1.16) \\
\end{array}$ & $\begin{array}{r}-0.530 \\
(0.83) \\
\end{array}$ \\
\hline Observaciones & 76,725 & 13,950 & 18,225 & 17,685 & 21,060 & 5,805 \\
\hline Municipios & 1,705 & 310 & 405 & 393 & 468 & 129 \\
\hline Efectos temporales & SÍ & SÍ & SÍ & SÍ & SÍ & SÍ \\
\hline
\end{tabular}

Cuadro 6. Estimación GLS

\begin{tabular}{|l|c|c|c|c|c|c|}
\hline \multicolumn{6}{|c|}{ Variable dependiente: Variación del logaritmo del número de préstamos personales por cada 10 mil adultos } \\
\hline & $\begin{array}{c}\text { Todos los } \\
\text { municipios }\end{array}$ & $\begin{array}{c}\text { Muy baja } \\
\text { marginación }\end{array}$ & $\begin{array}{c}\text { Baja } \\
\text { marginación }\end{array}$ & $\begin{array}{c}\text { Media } \\
\text { marginación }\end{array}$ & $\begin{array}{c}\text { Alta } \\
\text { marginación }\end{array}$ & $\begin{array}{c}\text { Muy alta } \\
\text { marginación }\end{array}$ \\
\hline Tasa objetivo & $-5.598^{*}$ & -2.768 & $-6.161^{* * *}$ & $-9.723^{* *}$ & $-10.46^{* * *}$ & -4.256 \\
disminuye rezagada & $(2.52)$ & $(1.51)$ & $(1.65)$ & $(3.57)$ & $(1.82)$ & $(2.64)$ \\
\hline
\end{tabular}

el nicho de mercado de los dos primeros es muy distinto al de Citibanamex, es muy probable que la competencia esté centrada entre Banco Azteca y Famsa. Sin embargo, los activos de este último solo representan el $18 \%$ de los activos de Banco Azteca por lo que es probable que el grado de competencia en el mercado de préstamos personales sea muy inferior al existente en el mercado de préstamos de nómina. 


\begin{tabular}{|c|c|c|c|c|c|c|}
\hline $\begin{array}{l}\text { Tasa objetivo } \\
\text { aumenta rezagada }\end{array}$ & $\begin{array}{c}-13.500^{* * *} \\
(1.66)\end{array}$ & $\begin{array}{c}-15.51^{* * *} \\
(1.01) \\
\end{array}$ & $\begin{array}{c}-14.97^{* * *} \\
(1.14) \\
\end{array}$ & $\begin{array}{c}-13.85^{* * *} \\
(2.39)\end{array}$ & $\begin{array}{c}-15.77^{* * *} \\
(1.18) \\
\end{array}$ & $\begin{array}{c}-10.91^{* * *} \\
(1.64) \\
\end{array}$ \\
\hline $\begin{array}{l}\text { Variación \% ITAEE } \\
\text { rezagada }\end{array}$ & $\begin{array}{c}-1.021^{* * *} \\
(0.29)\end{array}$ & $\begin{array}{c}-0.158 \\
(0.09)\end{array}$ & $\begin{array}{c}-0.424^{* *} \\
(0.15)\end{array}$ & $\begin{array}{c}-1.150^{* * * *} \\
(0.13)\end{array}$ & $\begin{array}{c}-1.788^{* * * *} \\
(0.26)\end{array}$ & $\begin{array}{c}-1.454^{* * *} \\
(0.10)\end{array}$ \\
\hline $\begin{array}{l}\text { Tasa de } \\
\text { morosidad } \\
\text { rezagada }\end{array}$ & $\begin{array}{c}-0.104^{* * *} \\
(0.02)\end{array}$ & $\begin{array}{c}-0.174^{* * *} \\
(0.01)\end{array}$ & $\begin{array}{c}-0.078^{* * *} \\
(0.01)\end{array}$ & $\begin{array}{c}-0.055^{* *} \\
(0.02)\end{array}$ & $\begin{array}{c}-0.016 \\
(0.02)\end{array}$ & $\begin{array}{c}-0.070^{* * *} \\
(0.01)\end{array}$ \\
\hline $\begin{array}{l}\text { Participación de } \\
\text { principales dos oferentes } \\
\text { rezagada }\end{array}$ & $\begin{array}{c}-0.235^{* * *} \\
(0.02)\end{array}$ & $\begin{array}{c}-0.338^{* * *} \\
(0.01)\end{array}$ & $\begin{array}{c}-0.388^{* * *} \\
(0.01)\end{array}$ & $\begin{array}{c}-0.382^{* * *} \\
(0.01)\end{array}$ & $\begin{array}{l}-0.160^{* * *} \\
(0.01)\end{array}$ & $\begin{array}{c}-0.026^{* *} \\
(0.00)\end{array}$ \\
\hline $\begin{array}{l}\text { Variable } \\
\text { dependiente } \\
\text { rezagada }\end{array}$ & $\begin{array}{c}-0.057^{* * *} \\
(0.01)\end{array}$ & $\begin{array}{c}-0.023^{*} \\
(0.01)\end{array}$ & $\begin{array}{c}-0.044^{* *} \\
(0.01)\end{array}$ & $\begin{array}{c}-0.0305^{*} \\
(0.01)\end{array}$ & $\begin{array}{c}-0.030^{*} \\
(0.01)\end{array}$ & $\begin{array}{c}-0.047^{* * *} \\
(0.01)\end{array}$ \\
\hline Índice de marginación & $\begin{array}{c}1.123^{* *} \\
(0.35)\end{array}$ & $\begin{array}{c}6.565^{* * *} \\
(0.64)\end{array}$ & $\begin{array}{c}4.927^{*} \\
(2.05)\end{array}$ & $\begin{array}{c}-0.224 \\
(1.39) \\
\end{array}$ & $\begin{array}{l}1.601 \\
(1.02)\end{array}$ & $\begin{array}{c}-1.391^{* * *} \\
(0.18)\end{array}$ \\
\hline Constante & $\begin{array}{c}32.30^{* * *} \\
(2.73) \\
\end{array}$ & $\begin{array}{c}42.17^{* * *} \\
(1.77) \\
\end{array}$ & $\begin{array}{c}41.81^{* * *} \\
(2.06) \\
\end{array}$ & $\begin{array}{c}43.08^{* * * *} \\
(2.76) \\
\end{array}$ & $\begin{array}{c}24.94^{* * *} \\
(2.15) \\
\end{array}$ & $\begin{array}{c}19.94^{* * * *} \\
(2.19) \\
\end{array}$ \\
\hline Observaciones & 63,683 & 13,588 & 16,942 & 13,158 & 14,964 & 5,031 \\
\hline Municipios & 1,481 & 316 & 394 & 306 & 348 & 117 \\
\hline Efectos temporales & SÍ & SÍ & SÍ & SÍ & SÍ & SÍ \\
\hline
\end{tabular}

Considerando que en ambos cuadros se encuentra que el parámetro de la variable dependiente rezagada tiene un signo negativo, se estimó un modelo ARDL con el fin de analizar la relación existente entre la variable dependiente y sus regresores, tanto a corto como a largo plazo ${ }^{10}$.

Para cada panel de municipios se hizo la estimación mediante tres métodos: Mean Group (MG), Dynamic Fixed Effects (DFE) y Pooled Mean Group (PMG). En el DFE los datos son reunidos en grupos y se asume que entre cada grupo solo puede variar el interceptos. En tanto que, en el método MG, los interceptos y coeficientes pueden variar entre grupos. Finalmente, la estimación PMG combina elementos de los dos anteriores, de manera que se asume que los efectos de largo plazo son los mismos entre grupos, pero los coeficientes para el corto plazo pueden variar. Sin embargo, al hacer las estimaciones, la prueba de Pesaran (2015) no pudo rechazar -en ningún caso- la hipótesis referente a la existencia de correlación contemporánea, lo cual nos orilló a utilizar el método de CSARDL.

En la Tabla 7 y 8 se presentan los resultados del modelo CS-ARDL11. Para estas estimaciones se eliminó del conjunto de variables explicativas a la tasa de informalidad estatal y en su lugar se introdujo el número de cuentas tradicionales como proporción del número total de cuentas en cada municipio. Esta variable ofrece rica información acerca de los clientes y sirve como aproximación del potencial de préstamos individuales que una institución bancaria podía ofrecer.

\footnotetext{
${ }^{10}$ Esta metodología admite variables con distinto orden de integración - como se reporta en el cuadro A del anexo. Por otro lado, la prueba de Westerlund (2005) muestra que en la mayoría de los municipios puede descartarse la posibilidad que no haya cointegración (cuadro $\mathrm{B}$ ) y los datos del cuadro $\mathrm{C}$ muestran el número óptimo de rezagos a utilizarse en cada panel.

${ }^{11}$ Considerando que la estimación es por máxima verosimilitud y la corrección de correlación se hace agregando como regresores a los promedios por periodo de las variables independientes, la combinación de 49 periodos y 75 mil observaciones vuelve muy oneroso el computo de las estimaciones con el panel de todos los municipios.
} 
En el caso de los préstamos de nómina, se observa que cambios en la tasa objetivo solo tiene afectaciones en los municipios de baja y muy baja marginación. Así, similar a lo que acontecía con las estimaciones GLS, se encuentra que los cambios de la postura monetaria solo impactan en pobladores que viven en municipios de baja y muy baja marginación. En lo que se refiere a los préstamos personales, variaciones en la tasa objetivo solo impactaron al volumen de créditos en el caso de los municipios de baja marginación. En lo que se refiere a otras variables, se observa que -similar a lo que se reportó en los cuadros 5 y 6 - los préstamos personales resultaron ser más sensibles en el corto plazo a los cambios en la actividad económica.

Cuadro 7. Estimaciones CS-ARDL

\begin{tabular}{|c|c|c|c|c|c|}
\hline \multicolumn{6}{|c|}{ Variable dependiente: Variación del logaritmo del número de préstamos nómina por cada 10 mil adultos } \\
\hline & $\begin{array}{c}\text { Muy baja } \\
\text { marginación }\end{array}$ & $\begin{array}{c}\text { Baja } \\
\text { marginación }\end{array}$ & $\begin{array}{c}\text { Media } \\
\text { marginación }\end{array}$ & $\begin{array}{c}\text { Alta } \\
\text { marginación }\end{array}$ & $\begin{array}{c}\text { Muy alta } \\
\text { marginación }\end{array}$ \\
\hline \multicolumn{6}{|l|}{ Coef. Largo plazo: } \\
\hline Tasa de interés objetivo & $\begin{array}{c}-0.002^{*} \\
(0.00)\end{array}$ & $\begin{array}{c}-0.001^{* *} \\
(0.00)\end{array}$ & $\begin{array}{l}0.000 \\
(0.00)\end{array}$ & $\begin{array}{l}0.007 \\
(0.00)\end{array}$ & $\begin{array}{l}-0.019 \\
(0.01)\end{array}$ \\
\hline Log. ITAEE & $\begin{array}{l}0.037 \\
(0.04)\end{array}$ & $\begin{array}{l}0.073 \\
(0.08)\end{array}$ & $\begin{array}{c}0.231^{* *} \\
(0.07)\end{array}$ & $\begin{array}{l}-0.051 \\
(0.48)\end{array}$ & $\begin{array}{r}-1.403 \\
(1.36)\end{array}$ \\
\hline Tasa de morosidad & $\begin{array}{r}-0.000 \\
(0.00) \\
\end{array}$ & $\begin{array}{r}-0.000 \\
(0.00) \\
\end{array}$ & $\begin{array}{l}0.000 \\
(0.00)\end{array}$ & $\begin{array}{l}0.000 \\
(0.00)\end{array}$ & $\begin{array}{l}0.000 \\
(0.00) \\
\end{array}$ \\
\hline $\begin{array}{l}\text { Participación de } \\
\text { principales dos oferentes }\end{array}$ & $\begin{array}{l}-0.00 \\
(0.00)\end{array}$ & $\begin{array}{l}0.000 \\
(0.00)\end{array}$ & $\begin{array}{c}-0.001^{*} \\
(0.00)\end{array}$ & $\begin{array}{r}-0.001 \\
(0.00)\end{array}$ & $\begin{array}{l}-0.002 \\
(0.00)\end{array}$ \\
\hline $\begin{array}{l}\text { Proporción cuentas } \\
\text { tradicionales }\end{array}$ & $\begin{array}{l}-0.000 \\
(0.00)\end{array}$ & $\begin{array}{l}0.000^{*} \\
(0.00)\end{array}$ & $\begin{array}{l}0.000 \\
(0.00)\end{array}$ & $\begin{array}{l}0.000 \\
(0.00)\end{array}$ & $\begin{array}{l}-0.001 \\
(0.00)\end{array}$ \\
\hline \multicolumn{6}{|l|}{ Coef. Corto plazo: } \\
\hline $\begin{array}{l}\text { Variación Tasa de interés } \\
\text { objetivo }\end{array}$ & $\begin{array}{c}-0.003^{* *} \\
(0.00) \\
\end{array}$ & $\begin{array}{c}-0.002^{*} \\
(0.00) \\
\end{array}$ & $\begin{array}{l}0.000 \\
(0.00) \\
\end{array}$ & $\begin{array}{r}-0.003 \\
(0.00) \\
\end{array}$ & $\begin{array}{l}-0.000 \\
(0.00) \\
\end{array}$ \\
\hline Variación Log. ITAEE & $\begin{array}{l}0.118^{*} \\
(0.05)\end{array}$ & $\begin{array}{l}0.154 \\
(0.08)\end{array}$ & $\begin{array}{c}0.355^{* * *} \\
(0.09)\end{array}$ & $\begin{array}{c}0.699 * * * \\
(0.12)\end{array}$ & $\begin{array}{l}0.055 \\
(0.39)\end{array}$ \\
\hline $\begin{array}{l}\text { Variación Tasa de } \\
\text { morosidad }\end{array}$ & $\begin{array}{l}0.000 \\
(0.00)\end{array}$ & $\begin{array}{l}0.000 \\
(0.00)\end{array}$ & $\begin{array}{l}0.000 \\
(0.00)\end{array}$ & $\begin{array}{l}0.000 \\
(0.00)\end{array}$ & $\begin{array}{c}0.002 \\
(0.002)\end{array}$ \\
\hline $\begin{array}{l}\text { Variación de Participación } \\
\text { principales dos oferentes }\end{array}$ & $\begin{array}{c}-0.001^{* * *} \\
(0.00)\end{array}$ & $\begin{array}{l}-0.001 \\
(0.00)\end{array}$ & $\begin{array}{c}-0.001^{* *} \\
(0.00)\end{array}$ & $\begin{array}{c}-0.001^{*} \\
(0.00)\end{array}$ & $\begin{array}{l}-0.001 \\
(0.00)\end{array}$ \\
\hline $\begin{array}{l}\text { Variación de Proporción } \\
\text { cuentas tradicionales }\end{array}$ & $\begin{array}{l}0.000 \\
(0.00)\end{array}$ & $\begin{array}{l}0.000 \\
(0.00)\end{array}$ & $\begin{array}{l}-0.000 \\
(0.00)\end{array}$ & $\begin{array}{r}-0.000 \\
(0.00)\end{array}$ & $\begin{array}{l}-0.001 \\
(0.00)\end{array}$ \\
\hline $\begin{array}{l}\text { Variable dependiente } \\
\text { rezagada }\end{array}$ & $\begin{array}{c}-0.239 * * * \\
(0.02)\end{array}$ & $\begin{array}{c}-0.130^{* * *} \\
(0.022)\end{array}$ & $\begin{array}{c}-0.133^{* * *} \\
(0.01)\end{array}$ & $\begin{array}{c}-0.129 * * * \\
(0.01)\end{array}$ & $\begin{array}{c}-0.133^{*} \\
(0.05)\end{array}$ \\
\hline Velocidad de ajuste & $\begin{array}{c}-0.235^{* * *} \\
(0.01)\end{array}$ & $\begin{array}{c}-0.299 * * * \\
(0.02)\end{array}$ & $\begin{array}{c}-0.306^{* * *} \\
(0.01)\end{array}$ & $\begin{array}{c}-0.287^{* * *} \\
(0.01)\end{array}$ & $\begin{array}{c}-0.290^{* * *} \\
(0.03)\end{array}$ \\
\hline Observaciones & 12,051 & 15,756 & 15,093 & 18,057 & 4,719 \\
\hline Municipios & 309 & 404 & 387 & 463 & 121 \\
\hline Efectos temporales & Sí & Sí & Sí & Sí & Sí \\
\hline
\end{tabular}




\begin{tabular}{|l|c|c|c|c|c|}
\hline CD (Pesaran, 2015) & $\begin{array}{c}10.50 \\
(0.00)\end{array}$ & $\begin{array}{c}1.87 \\
(0.06)\end{array}$ & $\begin{array}{c}10.78 \\
(0.00)\end{array}$ & $\begin{array}{c}2.95 \\
(0.00)\end{array}$ & $\begin{array}{c}1.72 \\
(0.08)\end{array}$ \\
\hline
\end{tabular}

Cuadro 8. Estimaciones CS-ARDL

\begin{tabular}{|c|c|c|c|c|c|}
\hline & $\begin{array}{c}\text { Muy baja } \\
\text { marginación }\end{array}$ & $\begin{array}{c}\text { Baja } \\
\text { marginación }\end{array}$ & $\begin{array}{c}\text { Media } \\
\text { marginación }\end{array}$ & $\begin{array}{c}\text { Alta } \\
\text { marginación }\end{array}$ & $\begin{array}{c}\text { Muy alta } \\
\text { marginación }\end{array}$ \\
\hline \multicolumn{6}{|l|}{ Coef. Largo plazo: } \\
\hline Tasa de interés objetivo & $\begin{array}{l}-0.043 \\
(0.04) \\
\end{array}$ & $\begin{array}{l}-0.027 \\
(0.02) \\
\end{array}$ & $\begin{array}{l}0.006 \\
(0.01) \\
\end{array}$ & $\begin{array}{r}-0.001 \\
(0.00) \\
\end{array}$ & $\begin{array}{r}-0.011 \\
(0.01) \\
\end{array}$ \\
\hline Log. ITAEE & $\begin{array}{l}-0.235 \\
(0.36) \\
\end{array}$ & $\begin{array}{l}1.940 \\
(1.66) \\
\end{array}$ & $\begin{array}{l}0.534 \\
(0.57) \\
\end{array}$ & $\begin{array}{l}1.227 \\
(0.72) \\
\end{array}$ & $\begin{array}{r}-1.578 \\
(1.00) \\
\end{array}$ \\
\hline Tasa de morosidad & $\begin{array}{c}-1.093^{* * *} \\
(0.01)\end{array}$ & $\begin{array}{c}-1.177^{* * *} \\
(0.01)\end{array}$ & $\begin{array}{c}-1.132^{* * *} \\
(0.02)\end{array}$ & $\begin{array}{c}-1.148^{* * *} \\
(0.01)\end{array}$ & $\begin{array}{c}-1.307^{* * *} \\
(0.04)\end{array}$ \\
\hline $\begin{array}{l}\text { Participación de principales } \\
\text { dos oferentes }\end{array}$ & $\begin{array}{l}-0.01 \\
(0.01)\end{array}$ & $\begin{array}{c}-0.001^{*} \\
(0.00)\end{array}$ & $\begin{array}{r}-0.001 \\
(0.00)\end{array}$ & $\begin{array}{l}0.002 \\
(0.00)\end{array}$ & $\begin{array}{l}0.001 \\
(0.00)\end{array}$ \\
\hline $\begin{array}{l}\text { Proporción cuentas } \\
\text { tradicionales }\end{array}$ & $\begin{array}{r}-0.000 \\
(0.00)\end{array}$ & $\begin{array}{r}-0.000 \\
(0.00)\end{array}$ & $\begin{array}{l}0.001 \\
(0.00)\end{array}$ & $\begin{array}{c}-0.001 \\
(0.00)\end{array}$ & $\begin{array}{l}-0.001 \\
(0.00)\end{array}$ \\
\hline \multicolumn{6}{|l|}{ Coef. Corto plazo: } \\
\hline $\begin{array}{l}\text { Variación Tasa de interés } \\
\text { objetivo }\end{array}$ & $\begin{array}{c}-0.003^{*} \\
(0.00) \\
\end{array}$ & $\begin{array}{c}-0.007^{*} \\
(0.00) \\
\end{array}$ & $\begin{array}{l}0.002 \\
(0.00) \\
\end{array}$ & $\begin{array}{l}0.001 \\
(0.00) \\
\end{array}$ & $\begin{array}{r}-0.005 \\
(0.01) \\
\end{array}$ \\
\hline Variación Log. ITAEE & $\begin{array}{c}0.632^{* * *} \\
(0.17)\end{array}$ & $\begin{array}{c}0.867^{* * *} \\
(0.23)\end{array}$ & $\begin{array}{c}1.335^{* * *} \\
(0.34)\end{array}$ & $\begin{array}{c}1.649^{* * *} \\
(0.44)\end{array}$ & $\begin{array}{r}-0.643 \\
(1.05) \\
\end{array}$ \\
\hline Variación Tasa de morosidad & $\begin{array}{l}0.001 \\
(0.00) \\
\end{array}$ & $\begin{array}{l}-0.001 \\
(0.00) \\
\end{array}$ & $\begin{array}{r}-0.000 \\
(0.00) \\
\end{array}$ & $\begin{array}{l}0.000 \\
(0.00) \\
\end{array}$ & $\begin{array}{l}0.001 \\
(0.00) \\
\end{array}$ \\
\hline $\begin{array}{l}\text { Variación de Participación } \\
\text { principales dos oferentes }\end{array}$ & $\begin{array}{c}0.002^{* *} \\
(0.00) \\
\end{array}$ & $\begin{array}{l}0.001 \\
(0.00)\end{array}$ & $\begin{array}{l}-0.000 \\
(0.00) \\
\end{array}$ & $\begin{array}{c}-0.002^{*} \\
(0.00)\end{array}$ & $\begin{array}{r}-0.001 \\
(0.00)\end{array}$ \\
\hline $\begin{array}{l}\text { Variación de Proporción } \\
\text { cuentas tradicionales }\end{array}$ & $\begin{array}{r}-0.000 \\
(0.00)\end{array}$ & $\begin{array}{c}-0.001^{*} \\
(0.00)\end{array}$ & $\begin{array}{r}-0.000 \\
(0.00)\end{array}$ & $\begin{array}{r}-0.002 \\
(0.00)\end{array}$ & $\begin{array}{r}-0.001 \\
(0.00)\end{array}$ \\
\hline $\begin{array}{l}\text { Variable dependiente } \\
\text { rezagada }\end{array}$ & $\begin{array}{c}-0.197^{* * *} \\
(0.02)\end{array}$ & $\begin{array}{c}-0.150^{* * *} \\
(0.02)\end{array}$ & $\begin{array}{c}-0.149^{* * *} \\
(0.028) \\
\end{array}$ & $\begin{array}{c}-0.170^{* * *} \\
(0.02)\end{array}$ & $\begin{array}{r}-0.033 \\
(0.04) \\
\end{array}$ \\
\hline Velocidad de ajuste & $\begin{array}{c}-0.093^{* * *} \\
(0.01) \\
\end{array}$ & $\begin{array}{c}-0.177^{* * *} \\
(0.01) \\
\end{array}$ & $\begin{array}{c}-0.132^{* * *} \\
(0.02) \\
\end{array}$ & $\begin{array}{c}-0.148^{* * *} \\
(0.01) \\
\end{array}$ & $\begin{array}{c}-0.307^{* * *} \\
(0.04) \\
\end{array}$ \\
\hline Observaciones & 12,324 & 15,288 & 11,856 & 13,299 & 4,407 \\
\hline Municipios & 316 & 392 & 304 & 341 & 113 \\
\hline Efectos temporales & Sí & Sí & Sí & Sí & Sí \\
\hline CD (Pesaran, 2015) & $\begin{array}{c}4.04 \\
(0.000)\end{array}$ & $\begin{array}{c}2.57 \\
(0.011)\end{array}$ & $\begin{array}{c}5.66 \\
(0.000)\end{array}$ & $\begin{array}{c}1.13 \\
(0.259)\end{array}$ & $\begin{array}{c}0.61 \\
(0.545)\end{array}$ \\
\hline
\end{tabular}




\section{Discusión de Resultados}

Ante choques macroeconómicos negativos, la primera reacción de los bancos centrales consiste en elevar la liquidez de los bancos con el fin de hacer posible un incremento en la oferta crediticia. Si bien hay distintas maneras de hacerlo, el más común es bajando la tasa objetivo. Con el fin de mostrar el impacto que tienen las alteraciones en la tasa objetivo sobre el producto es común utilizar el método de vectores autorregresivos para con base en ello construir funciones impulso-respuesta. Para el caso de México, estudios que utilizan esta metodología encuentran que el mecanismo crediticio amplifica el impacto de los cambios en la tasa objetivo. Sin embargo, dada la importante desigualdad existente en el país, ¿es este resultado válido a lo largo y ancho del país?; ¿hay alguna evidencia de que este tipo de acciones de política monetaria pudiera tener efectos en algunas zonas del país, pero no en otras? Estas son las preguntas que dieron lugar a este texto.

Haciendo uso de estimaciones mínimos cuadrados generalizados encontramos tres resultados. Primero, que las variaciones al alza en la tasa objetivo tienen un mayor impacto - sobre la tasa de crecimiento de los préstamos personales y de nómina- cuando dicha tasa se incrementa. Este resultado muy probablemente obedece a la existencia de costos de transacción asociados a la firma de un contrato. Segundo, en el caso de los préstamos de nómina, se halló que incrementos en la tasa de interés afectan en menor medida a los pobladores de los municipios de baja marginación. Y ante reducciones en la tasa de interés, la tasa de crecimiento de los préstamos crece más en estos mismos municipios. Tercero, los créditos personales reaccionan más a los cambios en la tasa objetivo y son más sensible a las variaciones de la actividad económica. Ello muy probablemente obedece a los menores costos de transacción en que se incurre para obtener un préstamo personal.

Ante las restricciones que impone la metodología de mínimos cuadrados generalizados, para evaluar las siguientes hipótesis se utilizó un modelo de tipo autorregresivo con retardos distribuidos de forma transversal. Dicha metodología permite observar la relación de corto y largo plazo entre la variable dependiente y sus regresores sin tener que asumir que el cambio en la tasa de interés deba ser homogéneo e independientemente del nivel previo y de la magnitud de su variación anterior. Con base en ella, obtenemos resultados que ratifican lo ya manifestado antes: el volumen de los préstamos personales y de los préstamos de nómina son sensibles a las modificaciones en la tasa objetivo solo cuando los pobladores viven en municipios de baja y muy baja marginación.

Los resultados aquí descritos se obtuvieron considerando la información para una temporalidad (segundo período 2011-segundo periodo 2019) en el que la economía mexicana creció sin sobresaltos a una tasa promedio del $2.5 \%$. Si en un periodo de estabilidad macroeconómica se obtiene como resultado que las variaciones en la tasa objetivo del Banco Central solo tienen efectos sobre el volumen de créditos personales y de nómina para los pobladores de municipios de muy baja marginación y baja marginación, podemos suponer que, en épocas de aguda contracción económica, el impacto de cambios en la postura monetaria sobre el volumen de préstamos será aún menor. Si ello es así, es necesario que la autoridad monetaria utilice nuevos instrumentos y apoye también a otras instituciones financieras no-bancarias para lograr que los préstamos lleguen a los pobladores de las zonas con media, alta y muy alta marginación. 


\section{Referencias}

[1] Amaral, P. (2017), Monetary Policy and Inequality. Economic Commentary, Federal Reserve of Cleveland. Recuperado de: https://www.clevelandfed.org/en/newsroomand- events/publications/economic-commentary/2017-economic-commentaries/ec-201701monetary-policy-and-inequality.aspx

[2] Auclert, A. (2019). Monetary Policy and the Redistribution Channel. American Economic Review, 109 (6), 2333-67. doi: 10.1257/aer.20160137

[3] Bernanke, B. (2015). Monetary Policy and Inequality. Recuperado de: https://www.brookings.edu/blog/ben-bernanke/2015/06/01/monetary-policy-andinequality/

[4] Bernanke, B., y M. Gertler (1995). Inside the black box: the credit channel of monetary policy transmission. Journal of Economic perspectives, 9(4): 27-48. doi:10.1257/jep.9.4.27

[5] Bernanke, B., y A. Blinder (1992). The Federal Funds Rate and the Channels of Monetary Transmission. American Economic Review, 82, 901-921. doi:10.3386/w3487

[6] Carpenter, S., y W. Rodgers III (2004), The Disparate Labor Market Impacts of Monetary Policy. Journal of Policy Analysis and Management, 23(4): 813-30. doi:10.1080/0023656042000329873

[7] Castillo, R. (2003). Restricciones De Liquidez, Canal De Crédito y Consumo en México. Economía Mexicana, 12(1), 65-101.

[8] Chudik, A., Mohaddes, K., Pesaran, M. H., y Raissi, M. (2016). Long-Run Effects in Large Heterogeneous Panel Data Models with Cross-Sectionally Correlated Errors. Essays in Honor of man Ullah (Advances in Econometrics), 36, 85-135.

[9] Colciago, A., A. Samarina y J. de Haan, (2019). Central bank policies and income and wealth inequality: A survey. Journal of Economic Surveys, 33(4), 1199-1231. doi:10.2139/ssrn.3184342

[10]

[11] Doepke, M. y M. Schneider (2006). Inflation and the Redistribution of Wealth. Journal of Political Economy, 114(6), 1069-1097. doi:10.21034/sr.355

[12] Edwards, F. y F. Mishkin (1995). The Decline of Traditional Banking: Implications for Financial Stability and Regulatory Policy. Federal Reserve Bank of New York Economic Policy Review, 1(2), 27-45. doi:10.3386/w4993

[13] Erosa, A. y G. Ventura (2002). On inflation as a Regressive Consumption tax. Journal of Monetary Economics, 49(4), 761-795. doi:10.2139/ssrn.199168

[14] Evgenidis, A. y A. Fasianos (2019). Monetary Policy and Wealth Inequalities in Great Britain: Assessing the role of unconventional policies for a decade of household data. Cornell University, arXiv:1912.09702v1 [econ.GN].

[15] Gornemann N., K. Kuester, y M. Nakajima (2012). Monetary Policy with Heterogeneous Agents. Federal Reserve Bank of Philadelphia, Working Paper no. 12-21.

[16] Heathcote, J., F. Perri, y G. Violante (2010). Unequal We Stand: An Empirical Analysis of Economic Inequality in the United States, 1967-2006. Review of Economic Dynamics, 13(1), 15-51. doi:10.3386/w15483

[17] Ibarra, R. (2016). How important is the credit channel in the transmission of monetary policy in Mexico? Applied Economics, 48(36), 3462-3484.

[18] doi:10.1080/00036846.2016.1139680

[19] Im, K. S., Pesaran, M. H., y Shin, Y. (2003). Testing for unit roots in heterogeneous panels.

[20] Journal of econometrics, 115(1), 53-74. doi:10.1016/s0304-4076(03)00092-7

[21] Mishkin, F. S. (1995). Symposium on the monetary transmission mechanism. Journal of Economic Perspectives, 9(4), 3-10. 
[22] Monnin, P., K. Koedijk y P. Loungani (2018). Monetary policy, macroprudential regulation and inequality: An introduction to the special section. Journal of International Money and Finance, 85, 163167. doi:10.1016/j.jimonfin.2017.11.003

[23] Pesaran, M. H., Shin, Y., y Smith, R. P. (1999). Pooled mean group estimation of dynamic heterogeneous panels. Journal of the American Statistical Association, 94(446), 621-634. doi:10.1080/01621459.1999.10474156

[24] Pesaran, M. H., y Smith, R. (1995). Estimating long-run relationships from dynamic heterogeneous panels. Journal of econometrics, 68(1), 79-113. doi:10.1016/0304- 4076(94)01644-f

[25]

[26] Pesaran, M. H. (2015). Testing weak cross-sectional dependence in large panels. Econometric Reviews, 34(6-10), 1089-1117. doi:10.1080/07474938.2014.956623

[27] Sidaoui, J., y M. Ramos-Francia (2008). The Monetary Transmission Mechanism in Mexico: Recent Developments. BIS Papers, 35, 363-394.

[28] Westerlund, J. (2005). New simple tests for panel cointegration. Econometric Reviews, 24(3), 297-316. doi:10.1080/07474930500243019

\section{Anexos}

\begin{tabular}{|l|c|c|c|c|}
\hline \multicolumn{1}{|c}{ Cuadro A: Pruebas de raíces unitarias (Im, Pesaran \& Shin, 2003) } \\
\cline { 2 - 5 } & \multicolumn{2}{|c|}{ Nómina } & \multicolumn{2}{c|}{ Personales } \\
\cline { 2 - 5 } & Nivel & $\begin{array}{c}\text { Primera } \\
\text { diferencia }\end{array}$ & Nivel & $\begin{array}{c}\text { Primera } \\
\text { diferencia }\end{array}$ \\
\hline \multirow{2}{*}{ Log. Número de créditos } & -8.09 & -51.02 & -6.46 & -42.61 \\
& $(0.000)$ & $(0.000)$ & $(0.000)$ & $(0.000)$ \\
\hline \multirow{2}{*}{ Tasa de interés objetivo } & 43.38 & -69.41 & 47.03 & -64.69 \\
\hline \multirow{2}{*}{ Log. ITAEE } & $(1.000)$ & $(0.000)$ & $(1.000)$ & $(0.000)$ \\
\hline \multirow{2}{*}{ Tasa de morosidad } & -0.21 & -2.48 & -0.39 & -2.66 \\
& $(0.417)$ & $(0.000)$ & $(0.348)$ & $(0.000)$ \\
\hline Participación principales & -34.51 & -74.52 & -25.92 & -53.35 \\
dos oferentes & $(0.000)$ & $(0.000)$ & $(0.000)$ & $(0.000)$ \\
\hline Proporción cuentas & 17.36 & 23.10 & -14.35 & -38.18 \\
tradicionales & $(0.000)$ & $(0.000)$ & $(0.000)$ & $(0.000)$ \\
\hline Nota: H0: Todos los paneles contienen una raíz unitaria; H1: Algunos paneles son estacionarios. \\
\hline
\end{tabular}




\begin{tabular}{|c|c|c|c|c|}
\hline \multicolumn{5}{|c|}{ Cuadro B: Pruebas de cointegración (Westerlund, 2005) } \\
\hline \multirow{2}{*}{$\begin{array}{l}\text { Tamaño de } \\
\text { población }\end{array}$} & \multicolumn{2}{|c|}{ Nómina } & \multicolumn{2}{|c|}{ Personales } \\
\hline & $\begin{array}{l}\text { Todos los } \\
\text { paneles }^{\text {a/ }}\end{array}$ & Algún panel ${ }^{\mathrm{b} /}$ & $\begin{array}{l}\text { Todos los } \\
\text { paneles }^{\text {a/ }}\end{array}$ & Algún panel b/ \\
\hline Muy bajo & $\begin{array}{c}-4.78 \\
(0.000)\end{array}$ & $\begin{array}{c}-7.16 \\
(0.000)\end{array}$ & $\begin{array}{c}-3.37 \\
(0.000)\end{array}$ & $\begin{array}{c}-7.51 \\
(0.000)\end{array}$ \\
\hline Bajo & $\begin{array}{c}-5.18 \\
(0.000)\end{array}$ & $\begin{array}{c}-7.24 \\
(0.000)\end{array}$ & $\begin{array}{c}-3.55 \\
(0.000)\end{array}$ & $\begin{array}{c}-6.50 \\
(0.000)\end{array}$ \\
\hline Medio & $\begin{array}{c}-3.98 \\
(0.000)\end{array}$ & $\begin{array}{c}-5.29 \\
(0.000)\end{array}$ & $\begin{array}{c}-3.58 \\
(0.000)\end{array}$ & $\begin{array}{c}-6.00 \\
(0.000)\end{array}$ \\
\hline Alto & $\begin{array}{c}-4.73 \\
(0.000)\end{array}$ & $\begin{array}{c}-6.41 \\
(0.000)\end{array}$ & $\begin{array}{c}-3.94 \\
(0.000)\end{array}$ & $\begin{array}{c}-5.21 \\
(0.000)\end{array}$ \\
\hline Muy alto & $\begin{array}{c}-2.23 \\
(0.013)\end{array}$ & $\begin{array}{c}-2.51 \\
(0.006)\end{array}$ & $\begin{array}{c}-2.61 \\
(0.005)\end{array}$ & $\begin{array}{c}-3.69 \\
(0.000)\end{array}$ \\
\hline \multicolumn{5}{|c|}{$\begin{array}{l}\text { Nota: } \\
\text { a/ H0: No hay cointegración; H1: Todos los paneles están cointegrados. } \\
\text { b/ H0: No hay cointegración; H1: Algunos paneles están cointegrados. }\end{array}$} \\
\hline
\end{tabular}

